Projections suggest 34,000 patients will be eligible for phase 2: in the first 12 weeks, in Picton Ward (eligible population 2471) 896 (36\%) individuals booked to attend the lung health check, where 230 (31\%) triggered the offer of a CT. To date 138 scans have been reported: 24 (17\%), had significant findings, of which $9(6 \%)$ require a 3 month and $3(2 \%) 12$ month repeat scan for nodules. Two individuals had confirmed cancer (both resected), with 2 further cases currently being worked up.

Of 406 patients (45\%) without previously diagnosed COPD, $180(44 \%)$ had abnormal spirometry, and have gone on to further diagnostics.

The complete Picton Ward data will be presented at the conference.

This innovative project is already improving access to respiratory healthcare in a deprived area of Liverpool, and should improve outcomes for lung cancer in this disadvantaged population. The project has been adopted by the national ACE program.

\section{P103 APPLES AND PEARS? A COMPARISON OF TWO SOURCES OF LUNG CANCER DATA IN ENGLAND}

${ }^{1} A$ Khakwani, ${ }^{1} \mathrm{R}$ Hubbard, ${ }^{2} \mathrm{R}$ Jack, ${ }^{2} \mathrm{~N}$ Wood, ${ }^{2} \mathrm{~S}$ Vernon, ${ }^{3} \mathrm{P}$ Beckett, ${ }^{3} \mathrm{~N}$ Navani, ${ }^{3} \mathrm{~S}$ Harden, ${ }^{3} \mathrm{R}$ Dickinson, ${ }^{3} \mathrm{I}$ Woolhouse. ${ }^{1}$ University of Nottingham, UK; ${ }^{2}$ National Cancer Registration Service, UK; ${ }^{3}$ Royal College of Physicians, London, UK

\subsection{6/thoraxjn-2016-209333.246}

Introduction In 2014, the contract to deliver the National Lung Cancer Audit (NLCA) was awarded to the Royal College of Physicians. Data were previously submitted using a bespoke dataset (LUCADA), but will now be submitted via the nationally mandated Cancer Outcome and Services Dataset (COSD) and linked to additional cancer registry datasets. For patients diagnosed in 2014, NLCA data were submitted using LUCADA for 132 of 151 English trusts. Trusts also submitted data via COSD and registry data were produced by the National Cancer Registration Analysis Service (NCRAS), providing the opportunity to compare both datasets for data completeness and reliability.

Methods We have linked the LUCADA and cancer registration datasets at patient level and assessed completeness of key patient variables including age, sex, stage, performance status and pathological confirmation, as well as recording/dates of treatment received. We assessed the inter-rater/data agreement of these variables using Cohen's kappa statistics (k). Finally, we carried out a qualitative assessment on a subset of cases to explore reasons why patients were represented in one dataset but not the other.

Results There were 26,001 patients in both datasets $194 \%$ of LUCADA data) with more in the registry dataset and not LUCADA than vice versa. Recorded sex and age were highly congruent, as was trust first seen which was the same in $96 \%$. 56\% of the patients had the same date of diagnosis, $74 \%$ were \pm 7 days and $86 \%$ were \pm 14 days of each other. The cancer registry data had a larger proportion of patients with missing PS (27\% vs $11 \%$ ) with agreement on PS (where available) being $97 \%$ $(\mathrm{k}=0.91)$. Agreement on stage was $94 \%(\mathrm{k}=0.81)$. Agreement for surgery, chemotherapy and radiotherapy was $0.86,0.88$ and 0.77 respectively. Details of the qualitative work and trust first seen algorithms will be provided in the presentation.

Conclusion Results suggest that cancer registry data accurately describe key patient features. Compared with LUCADA, the national cancer registry:

- identified more patients

\begin{tabular}{|c|c|c|c|c|}
\hline Key Variables & $\begin{array}{l}\text { Cancer registry } \\
\text { database } \mathbf{n}(\%)\end{array}$ & $\begin{array}{l}\text { LUCADA } \\
\text { database } \mathbf{n}(\%)\end{array}$ & $\begin{array}{l}\text { Agreement } \\
\%\end{array}$ & $\begin{array}{l}\text { Kappa } \\
\text { (к) }\end{array}$ \\
\hline \multicolumn{5}{|l|}{ Sex } \\
\hline Female & 11990 (46) & 11987 (46) & & \\
\hline Male & 14011 (54) & 14014 (54) & $99 \%$ & 0.99 \\
\hline \multicolumn{5}{|l|}{ Age } \\
\hline$<65$ & $6032(23)$ & 6025 (23) & & \\
\hline $65-80$ & $14249(55)$ & $14242(55)$ & & \\
\hline$>80$ & $5720(22)$ & $5734(22)$ & $99 \%$ & 0.99 \\
\hline \multicolumn{5}{|l|}{ Pathology } \\
\hline \multicolumn{5}{|l|}{ Confirmed } \\
\hline No & 6341 (24) & 7664 (29) & & \\
\hline Yes & $19660(76)$ & $18337(71)$ & $89 \%$ & 0.73 \\
\hline \multicolumn{5}{|l|}{ Lung Cancer } \\
\hline \multicolumn{5}{|l|}{ Type } \\
\hline Small Cell & 2975 (11) & 2958 (11) & & \\
\hline Carcinoid & 189 (1) & $234(1)$ & & \\
\hline Non-small cell & 22837 (88) & 22809 (88) & $97 \%$ & 0.87 \\
\hline \multicolumn{5}{|l|}{ Performance } \\
\hline \multicolumn{5}{|l|}{ Status } \\
\hline 0 & 3816 (15) & 4278 (16) & & \\
\hline 1 & $6550(25)$ & 7869 (30) & & \\
\hline 2 & 4025 (15) & $5109(20)$ & & \\
\hline 3 & 3553 (14) & 4527 (17) & & \\
\hline 4 & $1152(4)$ & $1424(5)$ & $97 \%$ & $0.91 \dagger$ \\
\hline Missing & 6905 (27) & 2794 (11) & $83 \%$ & $0.57 \dagger$ \\
\hline \multicolumn{5}{|l|}{ Stage } \\
\hline IA & 2976 (8) & $2226(9)$ & & \\
\hline IB & 2296 (6) & $1714(7)$ & & \\
\hline$\| A$ & 1405 (4) & 1087 (4) & & \\
\hline IIB & $1236(4)$ & 1025 (4) & & \\
\hline IIIA & 3981 (11) & 3330 (13) & & \\
\hline IIIB & 2844 (8) & 2470 (9) & & \\
\hline IV & $16758(47)$ & $12258(47)$ & $96 \%$ & $0.90 \dagger$ \\
\hline Missing & $4022(11)$ & $1891(7)$ & $94 \%$ & $0.81 \dagger$ \\
\hline
\end{tabular}

- has a higher proportion pathological confirmation

- identified more patients with surgery, chemotherapy and radiotherapy

- has a higher proportion of missing data for PS which could be due to data entry transition

\section{P104 RESULTS OF THE FIRST ANALYSIS OF NATIONAL LUNG CANCER AUDIT DATA BASED ON CANCER REGISTRATION DATA}

${ }^{1} \mathrm{P}$ Beckett, ${ }^{2} \mathrm{~A}$ Khakwani, ${ }^{2} \mathrm{R}$ Hubbard, ${ }^{3} \mathrm{~S}$ Vernon, ${ }^{3} \mathrm{R}$ Jack, ${ }^{3} \mathrm{~N}$ Wood, ${ }^{3} \mathrm{~B}$ Plewa, ${ }^{4} \mathrm{~N}$ McAndrew, ${ }^{1} \mathrm{R}$ Dickinson, ${ }^{1} \mathrm{~N}$ Navani, ${ }^{1} \mathrm{~S}$ Harden, ${ }^{1} \mathrm{I}$ Woolhouse. ${ }^{1}$ Royal College of Physicians, London, UK; ${ }^{2}$ University of Nottingham, UK; ${ }^{3}$ National Cancer Registration Service, UK; ${ }^{4}$ Wrexham Maelor Hospital, UK

\subsection{6/thoraxjnl-2016-209333.247}

Introduction The National Lung Cancer Audit (NLCA) has collected data for over 10 years, but in early 2015 a transition to using the Cancer Outcomes and Services Dataset (COSD) and cancer registration was begun and has now entirely superseded the legacy LUCADA dataset. An online portal (CancerStats) has 
been developed with a bespoke section providing near real time analysis of unprocessed COSD data for the NLCA. This portal currently focusses on data completeness, with plans to add process and treatment data in the near future. We report the results of the first 12 months of data collection using the new system (2015), and have compared this to the last year of LUCADA submissions (2014).

Methods The COSD was submitted monthly by English trusts on patients diagnosed with invasive lung cancer throughout 2015. This raw data was used to populate the data completeness tables on the CancerStats portal. An algorithm was developed to allocate a "trust first seen" to each patient record. Our presentation will include data from the final processed cancer registration records that have been validated using all available data sources within the National Cancer Registration Service (NCRAS). Welsh data submitted via their CANISC system will be available for our presentation.

Results 35,000 individual cases of invasive lung cancer were submitted by English Trusts. Data completeness results are shown in Table 1. Our final presentation will be updated with data from the processed cancer registration records that have been validated using all available data sources within the National Cancer Registration Service (NCRAS), as well as results from Welsh trusts.

Conclusion COSD submissions appear to capture more cases of lung cancer than LUCADA. During this transition period, the quality of the data was less good than previous years with significant variation across organisations. However, data completeness for stage and treatment is expected to be better than indicated since final registered cases use data from a variety of other sources. CancerStats offers the opportunity for teams to monitor their data quality and to iteratively improve their internal processes to deliver robust data for future years, in particular patient factors such as performance status which is not available elsewhere.

\begin{tabular}{lll}
$\begin{array}{l}\text { Abstract P104 Table 1 Comparison of LUCADA (2014) } \\
\text { cancer registration data (2015) }\end{array}$ \\
\hline $\begin{array}{lll}\text { National average (Range by Strategic Clinical } \\
\text { Network) }\end{array}$ & $\begin{array}{l}\text { LUCADA } \\
2014\end{array}$ \\
\hline $\begin{array}{l}\text { Number of } \\
\text { diagnoses }\end{array}$ & 33,465 & 27,995 \\
Gender & $100 \%$ & \\
Ethnicity & $86 \%(70-96)$ & $96 \%$ \\
Performance & $69 \%(59-76)$ & $\mathrm{N} / \mathrm{A}$ \\
Status & & $89 \%$ \\
FEV1\% & $24 \%(9-35)$ & \\
Smoking status & $43 \%(27-57)$ & $20 \%$ \\
Basis of Diagnosis & $95 \%(87-100)$ & $\mathrm{N} / \mathrm{A}$ \\
Pre-treatment & $72 \%(54-77)$ & $99 \%$ \\
stage & & $92 \%$ \\
Treatment & $83 \%(66-93)$ & $57 \%$ \\
modality & & \\
\hline
\end{tabular}

\section{P105 LUNG CANCER STAGING - ARE WE GETTING IT RIGHT?}

J Ibrahim, A Mukhopadhyay, V Lostarakos, A Mahmood, S Khan, N Maddekar, S Bikmalla, A Lea, C Satur, Q Abid, S Ghosh, M Haris. Royal Stoke University Hospital, Stoke-on-trent, UK

10.1136/thoraxjn-2016-209333.248
Introduction Despite significant advances in the diagnostic and staging modalities, lung cancer survival remains poor. Accurate staging and stratification of lung cancer is imperative to appropriate management. We reviewed the accuracy of staging in all patients who underwent surgical resection for confirmed or suspected lung cancer.

Methods Retrospective study of consecutive surgical resections over 5 year period between January 2010 and December 2014; patients referred from other hospitals were excluded due to lack of pre-operative staging information. Surgical database and preoperative diagnostic information was reviewed.

Results 298 patients underwent surgical resection, mean age 68 years (range 26-91), male 150 (50\%). All patients had staging CT. 108 (36\%) had EBUS/Bronchoscopy, 9 (3\%) had pleural aspiration, 39 (13\%) had CT guided lung biopsy, 8 (3\%) other tissue sampling* (pelvic lesion, subcutaneous lymph node, previous wedge biopsy \& exploratory thoracotomy). Mean time from staging CT to resection was 47 days. 48 (16\%) had histo-cytological confirmation of lung cancer prior to resection. 248 (83\%) were primary lung, 17 (6\%) metastatic lung tumours from other primaries (breast, colorectal, bladder and renal), 2 (1\%) lymphoma and $31(10 \%)$ benign. Of the 248 patients with lung primary (see Figure 1), pre-operative staging was available in 234; $60 / 234(26 \%)$ were down staged on post-operative staging, 54 (23\%)) upstaged and 120 (51\%) showed concordance.

Conclusion Despite the use of combined pre-operative assessment, staging accuracy was only 51\% and histo-cytological confirmation of lung cancer was only available in a small number of patients. Every effort should be made by the multidisciplinary team to accurately stage lung cancer to guide appropriate therapeutic intervention.

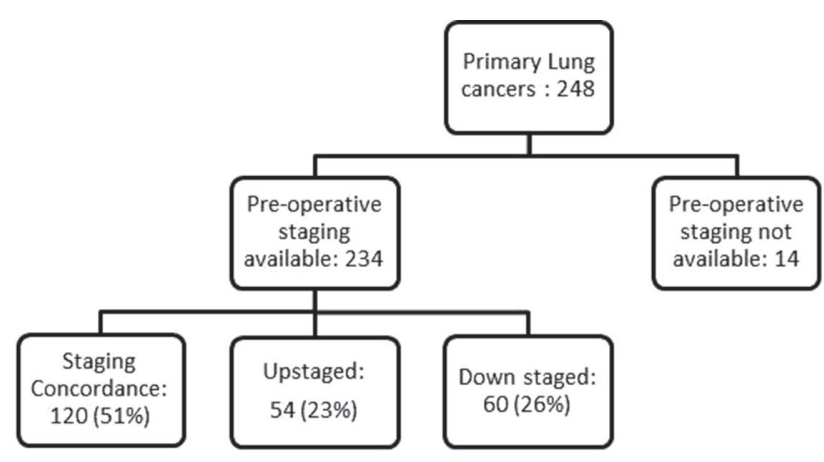

Abstract P105 Figure 1

\section{P106 IMPROVING FIVE YEAR SURVIVAL IN LUNG CANCER: SURVEYING PATIENTS AND CARERS, HCPS AND GPS}

R Steyn, MD Peake. UK Lung Cancer Coalition, London, UK

\subsection{6/thoraxjnl-2016-209333.249}

Introduction The United Kingdom Lung Cancer Coalition (UKLCC) was established in 2005 with the primary goal of doubling five-year survival rates in lung cancer by 2015. Estimates suggest that the UKLCC has met this goal in England, with improvements also seen in Scotland, Wales and Northern Ireland. The UKLCC is now looking to set a new ambition to substantially raise five-year survival rates by 2025 .

Method The UKLCC surveyed 102 patients and carers, 148 healthcare professionals, and 1,003 general practitioners (GPs) asking questions related to improvement of five-year survival rates for lung cancer. 